\title{
Digital Guest Speakers Who Stutter: Student Perceptions of Videoconferencing Within a Fluency Disorders Course
}

\author{
ErikX. Raj”*, Nagwa N. Ahmed', Charles D. Hughes² \\ ${ }^{1}$ Department of Speech-Language Pathology, School of Education, Monmouth University, West Long Branch, NJ; ${ }^{2}$ Department of Communication \\ Sciences and Disorders, Bowling Green State University, Bowling Green, $\mathrm{OH}$, United States
}

\begin{abstract}
Purpose: The purpose of this pedagogical research study was to understand how the use of audio/visual Internet-based communication systems, such as Skype, effect student learning, when digital guest speakers who have a fluency disorder (e.g., developmental stuttering) visit the classroom via videoconferencing technology.
\end{abstract}

Methods: A mixed-method approach was used to explore if the use of videoconferencing technology was a valuable method of supplemental instruction for graduate-level speech-language pathology students in a Fluency Disorders course. Twenty-six students enrolled in the course participated in this study and provided numerical and descriptive responses to questions in an optional and anonymous paper-based, pre and post survey. Throughout the course, four guest speakers of varying ages who were people who stutter were brought in, via Skype, and participated in 20-30-minute semi-structured interviews that explored the attitudes and beliefs of people who stutter.

Results: Paired sample t-tests revealed that students rated their knowledge of stuttering and confidence to work with populations with fluency disorders as significantly higher after interacting with the digital guest speakers. Thematic analysis revealed 3 major themes of the students' perceptions of utilizing videoconferencing technology: (1) Innovative (2) Informative and (3) Insightful.

Conclusions: Findings from the data suggest the use of videoconferencing technology to present students with digital guest speakers who have a fluency disorder and how that learning experience seems to benefit the students. Students reportedly gained a deeper understanding and perspective on the subject matter through the real-time interactions that existed between the digital guest speakers, the professor, and the students.

Keywords: Stuttering, Fluency disorders, Graduate education, Higher education, Pedagogy, Scholarship of teaching and learning, Videoconferencing, Teaching and learning strategies

\section{INTRODUCTION}

Stuttering is a fluency disorder where a person's forward flow of speech is temporarily interrupted during speaking situations [1]. This type of speech is often characterized by part-word and monosyllabic word repetitions, prolongations of speech sounds, and/or blocks in speech sounds that are audible or inaudible [2]. In addition to the behavioral speech components of this fluency disorder, psychosocial aspects of stuttering might

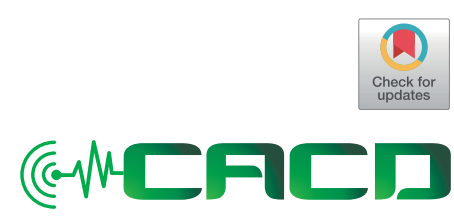

Received: October 27, 2017

Accepted: October 27, 2017

Correspondence:

Erik X. Raj

Department of Speech-Language Pathology, School of Education,

Monmouth University, 400 Cedar Avenue, West Long Branch, NJ 07764 United States

Tel: $+732-923-4638$

Fax: +732-263-5970

E-mail: eraj@monmouth.edu

(C) 2017 The Korean Association of SpeechLanguage Pathologists

This is an Open Access article distributed under the terms of the Creative Commons Attribution Non-Commercial License (http:// creativecommons.org/licenses/by-nc/4.0/) which permits unrestricted non-commercial use, distribution, and reproduction in any medium, provided the original work is properly cited. 
exist within a speaker that could include negative thoughts, feelings, and emotions that directly relate to the interruptions in the person's speech [3]. Speech-language pathologists are the professionals who specialize in the evaluation, diagnosis, and treatment of fluency disorders, and in particular, stuttering [4].

Past research has found that a substantial amount of speech-language pathologists do not feel adequately prepared to provide therapy to people who stutter (PWS) $[5,6]$. It is not uncommon for speech-language pathologists to report being unaware of certain basic stuttering-related knowledge points [6] and also having limited levels of success when assessing and treating certain populations of PWS [5]. Additionally, a number of students studying to become speech-language pathologists discussed their education and how they believed it had not sufficiently prepared them to clinically work with PWS [7]. Some of these findings could be explained by the discovered educational trends that seem to exist in a number of colleges and universities where students enrolled in speech-language pathology programs receive little to no opportunities to engage in learning experiences with PWS [8, 9]. This alarming information, which pertains to the ways that academic and clinical education in fluency disorders are set up, should be reviewed and reevaluated in the hopes that potential changes to the education of stuttering might better prepare future clinicians to be able to confidently and successfully evaluative, diagnose, and treat PWS upon graduation $[10,11]$.

A digital technology that could be explored that might allow for students to engage in learning experiences with PWS is videoconferencing. Videoconferencing is a synchronous, video-based connection that allows for two or more people to communicate to one another, at a distance, through the Internet. This robust type of digital communication allows all parties involved to not only hear the intended verbal output, but also see the visual body language and facial expressions that often coincide with verbal communication intents [12]. Videoconferencing started to gain worldwide popularity and mass adoption during the beginning of the 21st century because of increases in high-speed Internet access, and advancements in videoconferencing software that are low to nocost and easy to set up $[13,14]$. As long as both communication partners have access to an Internet-enabled computer or smart mobile device, they can download one of many software applications (e.g., Adobe Connect, Cisco WebEx, and Apple FaceTime) that will allow for videoconferencing to occur $[13,15,16]$.
One of the most popular videoconferencing software applications currently available for download is Skype [16]. Professors have started to view Skype as an effective educational tool that could be used to enhance learning within the classroom setting $[13,17]$. Additionally, students have reported Skype to be a valid teaching and learning tool that they believed professors should utilize, in some capacity, within their courses [18]. Through the use of Skype and intentionally videoconferencing with specific people who are relevant to a given course, it has been found that students were able to gain a deeper understanding of course content that helped them to be able to put their learning into context [19].

Today's 21st century students reportedly appreciate professors who do not only use traditional lectures as the single way for sharing knowledge. They have positively stated that when they are presented with a combination of video-based digital lectures from experts, as well as other non-traditional classroom activities, those learning experiences are more meaningful and useful to them [20]. Similarly, speech-language pathology students have shared positive remarks with regard to their learning within courses that featured therapy-related video presentations where they had the opportunity to see and hear peoples' specific communication difficulties $[11,21]$ These findings suggest the potential benefits of using Skype within the classroom setting as a means to enable students to engage in various video-based learning experiences.

Videoconferencing ability provided by Skype opens numerous opportunities for professors who teach a course in fluency disorders to invite a number of PWS to digitally visit the classroom as guest speakers. During these visitations, PWS can have open and honest discussions about what stuttering is with the class and answer any questions that students might have. It is the belief of these researchers that digital guest speakers who are PWS could play a significant role in improving the educational experience of students in a fluency disorders course. Through Skype, PWS are able to easily share, in real-time, valid information with students that directly relates to them, as communicators, and their life experiences with having a fluency disorder. By watching and listening to PWS through videoconferencing, students might gain access to a significant amount of real-world knowledge and advice from these digital guest speakers that could help to better prepare them to evaluate, diagnose, and treat PWS in the future.

Currently, there are no instances of published research that specifically focuses on exploring the use of introducing PWS as digital guest speakers in a fluency disorders course and the 
impact it may or may not have on the overall learning experience of the students. Most of the published studies that look into the perceived benefit of videoconferencing within the classroom setting have been conducted in fields unrelated to speech-language pathology, thus, making it clear that there is a need for more evidence-based research to be pursued in this area of educating students about fluency disorders. The utilization of videoconferencing has shown much promise in the past and it is crucial that future investigations begin to determine if it can be an appropriate addition to the academic and clinical education of fluency disorders. Therefore, the primary purpose of this pedagogical research study is to explore the thoughts and feelings of speech-language pathology students who have the opportunity to be a part of a fluency disorders course where the professor utilizes videoconferencing technology during classes to bring in digital guest speakers who are PWS.

To guide this study, the following questions will be addressed: (1) In what ways do students perceive classroom learning through videoconferencing technology? (2) In what ways are students' learning experiences affected by having digital guest speakers who are PWS digitally visit the classroom via videoconferencing technology? It is hypothesized that listening to and interacting with the digital guest speakers who are PWS will increase the students' overall knowledge of stuttering and ultimately, improve their confidence in evaluating, diagnosing, and treating PWS.

\section{METHODS}

\section{Procedure}

Four PWS were contacted by the professor (first author) of the fluency disorders course at Monmouth University. These PWS, who were all personal friends of the professor, were asked if they would consider being a digital guest speaker, via Skype, in the fluency disorders course during a designated date and time. It was explained to the individuals that because they are PWS, they have a great deal of stuttering-related knowledge and experiences that could be shared with the class that perfectly coincides with the course content. Additionally, it was mentioned by the professor that the stutteringrelated knowledge and experiences that each of the individuals possessed could potentially increase student interest, engagement, and retention of the stuttering-related course material.

Continuing on, the professor mentioned that each person's individual videoconferencing session would last approximately 20 to 30 minutes and would follow a semi-structured interview format (see Appendix A for a copy of the protocol). The semi-structured interview format would be led by the professor and observed by the students. The semi-structured interview questions were modeled in part after that of Koutsodimitropoulos et al. [7] who were interested in exploring the attitudes and beliefs of speech-language pathology students toward PWS. However, the questions by Koutsodimitropoulos et al. [7] were adapted to specifically include aspects related to this study. Additionally, toward the end of each person's individual videoconferencing session, for approximately $10 \mathrm{~min}$ utes, students would have the opportunity to ask specific questions to the person who stutters. Each of the four PWS accepted the invitation to be interviewed and four different days of class were set aside where each class session concluded with one of the digital guest speakers participating in a semi-structured interview.

In an effort to present the students with a variety of viewpoints, the professor chose to reach out to a diverse group of PWS that consisted of people of different ages. The age ranges of the PWS within the study were a male in his 20s, a female in her 30s, a male in his 40s, and a male in his 60s. The decision to intentionally choose a diverse age range of PWS was made in part because of Steyl et al. [11] who chose to present students in a fluency disorders course with a handful of teletherapy videos of PWS who were diverse in geographic locations. Because all of those PWS were from different countries, students in that fluency disorders course were able to discuss cultural differences that were noticed.

The location of the fluency disorders course for this study was in a classroom that contained an Internet-enabled computer, as well as a projector with speakers. Prior to the course officially starting, the professor downloaded Skype onto the computer and made a test videoconferencing call to ensure that Skype, as well as the projector and speakers, worked accordingly. On the first day of the fluency disorders course when all of the students were present, a verbal explanation about the research initiative was read aloud by the professor (see Appendix B for a copy of the script).

\section{Participants}

Participants in this study included 26 students who completed optional and anonymous paper-based pre and post-surveys (see Appendices C and D for copies of the surveys). All participating students were matriculated in the graduate-level 
speech-language pathology program at Monmouth University. In order to be eligible for the research study, participants must have been enrolled in the EDL-650: Fluency Disorders course during the duration of the study. The completion rate for both pre and post-surveys was $100 \%$.

\section{Data collection}

A mixed-methods approach was utilized in this study to gather data. This particular approach is common for studies that include a quantitative method to collect number-based data and a qualitative method to collect word-based data [22]. One of the main benefits to conducting mixed-methods research is that it was been known to increase researchers' confidence in the data and the findings because the variety of data allows for confirmation and comprehension of results [23]. Additionally, the use of a mixed-methods approach has been found to enhance the understanding of individuals' perceptions related to the subject of stuttering [7,24].

The 26 participants provided numerical and descriptive responses to the pre and post-surveys. The surveys were created as a means for obtaining responses to inquiries that directly related to the research questions. The surveys were modeled in part after that of Plumb [21] who was interested in examining speech-language pathology students' perceptions of interacting with a specific social networking website during a child language course in speech-language pathology. However, the surveys by Plumb [21] were adapted to specifically include aspects related to the current study.

\section{Data analysis}

For the quantitative data that were collected, paired sample t-tests were computed for mean scores on measures that related to potentially discovering any differences in student reported learning experiences. For the qualitative data that were collected, the theoretical approach of grounded theory was used as a way to thoroughly explain and describe the given phenomena being studied [25]. The intentional act of constantly comparing the data typically allows for a straightforward set of plausible hypotheses and theories to be generated by researchers [26].

Systematic coding procedures were used as a way to begin the process of comparing and analyzing the qualitative data [27]. Specifically, line-by-line open coding of text usually results in being able to connect meaning to the data [28]. The style of the line-by-line coding that was executed during this study was similar to work done by Bowen [29]. To open code the data, all of the text within the pre and post-surveys were grouped together into manageable sentence-based presentations. After multiple viewings of the newly parsed out sentences by two independent reviewers, key words and phrases were underlined that related to the perceptions of classroom learning through videoconferencing technology. By consistently reviewing the key words and phrases, it allowed for the researchers to notice the emerging themes suggested by the data. Through thematic analysis, the emerging themes were reviewed and discussed until ultimately, a group of major themes were decided upon that were all applicable to the research questions [30].

\section{RESULTS}

All 26 participants reported that, in the past, they have been exposed to physical guest speakers who have come into their undergraduate and graduate classes. However, none of the participants reported to have ever been exposed to digital guest speakers through the use of any videoconferencing technologies. This section is organized according to the two research questions.

Research Question 1: In what ways do students perceive classroom learning through videoconferencing technology?

A thematic analysis was conducted on the participants' responses to determine major themes. These themes fell into three major categories: Innovative, Informative, and Insightful. In regard to the major categories, 11 of the 26 participants (42.3\%) made a comment about how videoconferencing technology was creative and engaging (Innovative), 14 of the 26 participants (53.8\%) made a comment about how videoconferencing technology enabled them to be presented with useful information (Informative), and 18 of the 26 participants (69.2\%) made a comment about how videoconferencing technology enabled them to achieve a deeper understanding of information (Insightful). The following are representative quotes of the participants' responses:

\section{Innovative}

- "It keeps the class exciting and engaging."

- "It's a great way to connect with people in a real-life, realtime way."

- "It is more interactive [than a textbook]."

- "It allows you to talk to others all over the world to get different opinions." 


\section{Informative}

- "It was informative to talk to a live person [who stutters] who could answer questions."

- "It was a very informative experience."

- "Every speaker had something new to add to our education."

- "It was such a unique and highly educational way to present the material to us."

\section{Insightful}

- “[Digital guest speakers who are PWS allow students to better] bridge the gap between real-life and textbook knowledge."

- "It is one thing to read about a disorder and the effects it has on a person, but it is much easier to understand these effects when you hear it, first hand [from the digital guest speakers who are PWS]."

- "Having digital access to people who experience stuttering in their daily lives was incredibly insightful. Listening to their perspective on what it's like to be a PWS added an entirely new dimension to the course."

- "It expanded my horizon of knowledge related to stuttering."

\section{Research Question 2: In what ways are students' learning experiences affected by having digital guest speakers who are PWS digitally visit the classroom via videoconferencing technology?}

Paired sample t-tests were computed for mean scores on mea- sures to potentially discover any differences in student reported learning experiences. Participants were asked to rate their stuttering-related knowledge level on a scale from 1-5 (1 indicating extremely knowledgeable and 5 not at all knowledgeable) before and after being exposed to digital guest speakers who are PWS. Prior to exposure, 6 of the 26 participants $(23.1 \%)$ reported that they were not at all knowledgeable on the subject of stuttering, 15 of the 26 participants $(57.7 \%)$ reported that they were slightly knowledgeable on the subject of stuttering, and 5 of the 26 participants (19.2\%) reported that they were moderately knowledgeable on the subject of stuttering. After exposure, 1 of the 26 participants (3.8\%) reported that they were moderately knowledgeable on the subject of stuttering, 19 of the 26 participants (73.1\%) reported that they were quite knowledgeable on the subject of stuttering, and 6 of the 26 participants $(23.1 \%)$ reported that they were extremely knowledgeable on the subject of stuttering. The mean score before was $4.04(S D=.662)$ and the mean score after was $1.81(S D=.491)$. Results indicated that the participants rated their stuttering-related knowledge levels significantly higher than before being exposed to digital guest speakers who are PWS, $\mathrm{t}(25)=4.04, p<0.001, \mathrm{~d}=1.62$ (Figure 1).

Additionally, participants were asked to rate how much they felt their stuttering-related knowledge improved, as a result of being exposed to digital guest speakers who are PWS, on a scale from 1-5 (1 indicating a great deal and 5 indicating none at all). It was found that 17 of the 26 participants (65.4\%) reported that the digital guest speakers who are PWS had a great deal of impact on their learning, 7 of the 26 participants

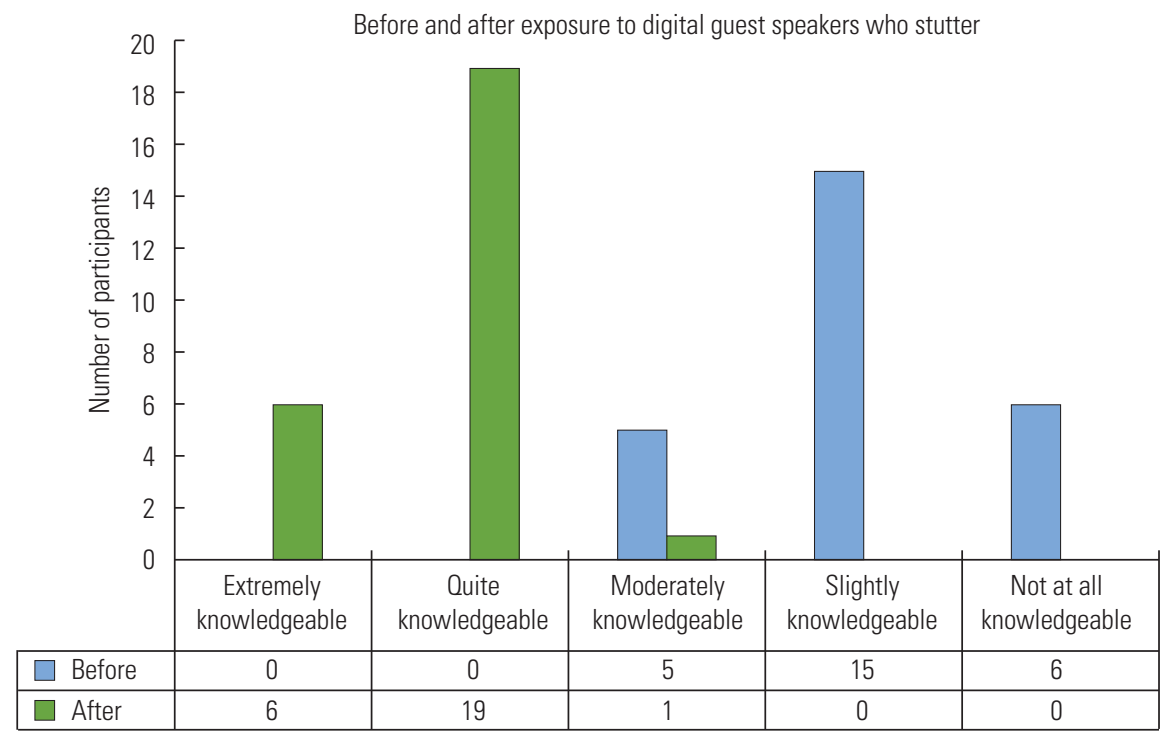

Figure 1. Displays the levels of stuttering knowledge both before and after exposure to digital guest speakers who stutter. 


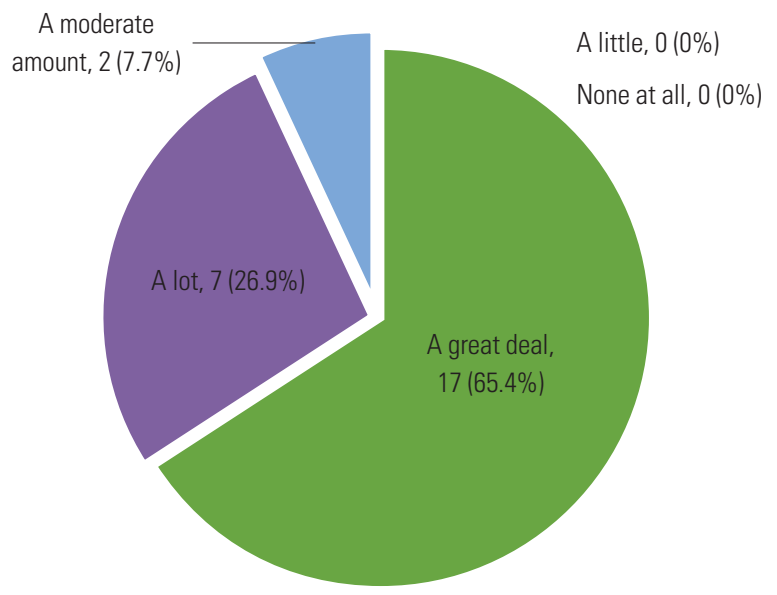

Figure 2. Displays the reported percentages of knowledge increase as a result of being exposed to the digital guest speakers who stutter.

(26.9\%) reported that the digital guest speakers who are PWS had a lot of impact on their learning, and 2 of the 26 participants $(7.6 \%)$ reported that the digital guest speakers who are PWS had a moderate amount of impact on their learning. No participants reported that the digital guest speakers who are PWS had a little to no impact on their learning (Figure 2).

\section{DISCUSSION}

The primary purpose of this pedagogical research study was to explore the thoughts and feelings of speech-language pathology students who had the opportunity to be a part of a fluency disorders course where the professor utilized videoconferencing technology during classes to bring in digital guest speakers who are PWS. The findings of this study suggest that the use of videoconferencing technology to present students with digital guest speakers who are PWS is beneficial to the learners and has a positive impact on the students' learning experience. These results will be further discussed in relation to the current study.

When students were asked how they perceived classroom learning through videoconferencing technology, one major theme in their responses was that it was "innovative." Several students mentioned that they felt the videoconferencing technology kept the class "exciting and engaging" and how it was "a great way to connect with people in a real-life, real-time way." Similar responses were uncovered by Maor and Currie [17] where students mentioned how Skype was a motivating factor for them during their learning experiences and how it was beneficial for them to use Skype to exchange ideas with others, at a distance, “because you can't meet up face-to-face all the time" (p. 10). Thanks to the innovation of videoconferencing technology, and more specially Skype, students have the ability to digitally connect and share with others that are relevant to the subject matter that is associated with their given class.

The results of this study also revealed that students viewed learning through videoconferencing technology as "informative." Students mentioned that "every speaker had something new to add to our education" and that it was a "unique and highly educational" experience. Similar findings were discovered by Nouri [20] who examined the use of video as a learning tool for assimilating knowledge. Video presentations within the classroom setting positively correlated to increased and effective learning. It should also be mentioned that Nouri revealed how students strongly agreed that it was useful for their learning to be able to pause and rewind the videos that they were presented with. Nouri's [20] findings that related to pausing and rewinding videos closely connects to a student's comment within this study that was, "It was informative to talk to a live person [who stutters] who could answer questions." When a student asks a question to a guest speaker during a videoconferencing experience, that student is arguably pausing the moment of teaching in order to gain more knowledge. Additionally, if the knowledge delivered to the student is presented in a way that is misunderstood or confusing, that student can request clarification, which is arguably rewinding the moment of teaching in order to fully understand the knowledge.

Another overwhelming theme of responses that was revealed during this study was that students felt that the videoconferencing technology experience was "insightful," causing them to have a deeper understanding of the subject matter. One student stated that the interaction between classmates and the digital guest speakers allowed students to "bridge the gap between real-life and textbook knowledge" which is a fundamental aspect of the overall educational experience. Similar data were collected by Steyl et al. [11] who found that interacting with people who stutter helped students to have a deeper understanding of stuttering because it aided in the learners ability to be "directly in touch with the realities being studies (p. 171)." Being able to bridge that gap between what is learned in a classroom and applying it in a real-life scenario is a skill that comes with experience, and the fact that some students in the current study reported to have a head start on this gives evidence to the point that having exposure to digital guest speakers who stutter relay their knowledge onto stu- 
dents is, indeed, a beneficial practice that could be described as an "eye-opening (experience) for students and professionals alike (10, p. 20)."

When students were asked how they were affected by having digital guest speakers who are PWS digitally visit the classroom via videoconferencing technology, the results revealed that students that participated in the study rated their knowledge on the subject of stuttering as being significantly higher than before having exposure to the digital guest speakers who are PWS. A majority of students who rated their knowledge as "not at all knowledgeable" and "slightly knowledgeable" before having exposure to the digital guest speakers who are PWS subsequently rated their knowledge on the topic of stuttering as "moderately knowledgeable," "quite knowledgeable," and "extremely knowledgeable." These positive results are indicative of the notion that digital guest speakers who are PWS were beneficial to the education of speech-language pathology students.

\section{Implications}

The current study suggests that exploring and utilizing videoconferencing technologies within the classroom setting are beneficial as a means of delivering additional education to students studying to become speech-language pathologists. These findings present several educational implications when working as an educator of college-aged students. One implication is that educators can implement these videoconferencing opportunities in the everyday-classroom setting when speaking about the subject of stuttering as a modality to help learners gain another perspective on the subject. If educators choose to implement this type of educational experience, the outcome can have a positive effect on the students' overall educational experience by helping them to better understand the different perceptions and viewpoints of stuttering from a diverse group of PWS from various geographical locations. Furthermore, learners can choose to seek more knowledge on the subject of stuttering due to the fact that the digital guest speakers may spark an interest in the leaners that might not have been there prior to having exposure to digital guest speakers who are PWS.

\section{Limitations}

A few limitations of this study are worth noting. First, the participants were current students of the first author, who was the professor of the fluency disorders course. It is possible that the positive outcome of this study could be attributed, in part, to the natural bias of the participants. That being said, however, the questionnaire was entirely anonymous, and responses to the questionnaire could not have any effect on the outcome of the students' grades in the fluency disorders course. Even with the above-mentioned limitations, the study still offers support that videoconferencing technology for students are beneficial as a means of an education that is able to increase the knowledge and exposure to the subject of stuttering.

\section{Future research}

It is recommended that future researchers continue to examine the thoughts and feelings of students, as they relate to videoconferencing technology and how this technology can be utilized within the classroom. Emphasis should be placed on exploring the effect of other digital guest speakers within additional courses taken by speech-language pathology students. Possible digital guest speakers that could be introduced to students could include those who have other communication difficulties, such as expressive and/or receptive language disorders, motor speech disorders, disorders of voice and resonance, and those who utilize augmentative and alternative means of communication.

\section{REFERENCES:}

1. Van Riper C. The nature of stuttering. Englewood Cliffs, NJ: Prentice-Hall. 1971.

2. Yairi E, Ambrose NG. Early childhood stuttering for clinicians by clinicians. Austin, TX: Pro Ed. 2005.

3. Quesal RW. Stuttering research: Have we forgotten the stutterer? Journal of Fluency Disorders. 1989;14(3):153-164.

4. American Speech-Language-Hearing Association. Scope of Practice in Speech-Language Pathology [Scope of Practice]. Available from www.asha.org/policy. 2016.

5. Brisk DJ, Healey EC, Hux KA. Clinicians' training and confidence associated with treating school-age children who stutter: a national survey. Language, Speech, and Hearing Services in Schools. 1997;28(2):164-176.

6. Tellis GM, Bressler L, Emerick K. An exploration of clinicians views about assessment and treatment of stuttering. Perspectives on Fluency and Fluency Disorders. 2008;18(1):16-23.

7. Koutsodimitropoulos E, Buultjens M, St. Louis K, Monfries M. Speech pathology student clinician attitudes and beliefs towards people who stutter: a mixed-method pilot study. Journal of Fluency Disorders. 2016;47:38-55.

8. Yaruss JS. Current status of academic and clinical education in fluency disorders at ASHA-accredited training programs. Journal of Fluency Disorders. 1999;24(3):169-183.

9. Yaruss JS, Quesal RW. Academic and clinical education in fluency disorders: An update. Journal of fluency disorders. 2002;27(1):43- 
63.

10. Boyle MP, Daniels DE, Hughes CD, Buhr AP. Considering disability culture for culturally competent interactions with individuals who stutter. Contemporary Issues in Communication Science and Disorders. 2016;43:11-22.

11. Steyl NA, Klein JF, Howell ML, Dalton JC. Increasing knowledge and skills of graduate students in a fluency disorders course. Contemporary Issues in Communication Science and Disorders. 2016;43:164-173.

12. Shylaja EA, Ravindran K. Teaching and learning grammar for teens using technological tools. Language in India. 2014;14(10): 18-27.

13. Courts B, Tucker J. Using technology to create a dynamic classroom experience. Journal of College Teaching \& Learning Online. 2012;9(2):121-128.

14. Goncalves R, Ribeiro R. Skype and the new regulatory framework. Communications and Strategies. 2005;59:141-158.

15. Charron K, Raschke R. Student perceptions and experiences using Jing and Skype in an Accounting Information Systems Class. Journal of Education for Business. 2014;89(1):1-6.

16. Garner JT, Buckner MM. Skyping Class: Using Videoconferencing in Organizational Communication Classes. Communication Teacher. 2013;27(1):1-5.

17. Maor D, Currie JK. The use of technology in postgraduate supervision pedagogy in two Australian universities. International Journal of Educational Technology in Higher Education. 2017;14(1):115.

18. Gros B, Lopez M. Students as co-creators of technology-rich learning activities in higher education. International Journal of Educational Technology in Higher Education. 2016;13(28):1-13.

19. Smith EE. Social media in undergraduate learning: categories and characteristics. International Journal of Educational Technology in Higher Education. 2017;14(1):1-24.
20. Nouri J. The flipped classroom: for active, effective and increased learning-especially for low achievers. International Journal of Educational Technology in Higher Education. 2016;13(1):33-42.

21. Plumb AM. Student perceptions of social networking as a supplemental learning tool in the communication disorders classroom. Contemporary Issues in Communication Science and Disorders. 2013;40:170-179.

22. Greene JC, Caracelli VJ, Graham WF. Toward a conceptual framework for mixed-method evaluation designs. Educational Evaluation and Policy Analysis. 1989;11(3):255-274.

23. Dunning H, Williams A, Abonyi S, Crooks V. A mixed method approach to quality of life research: A case study approach. Social Indicators Research. 2008;85(1):145-158.

24. Hughes S, Gabel R, Irani F, Schlagheck A. University students' explanations for their descriptions of people who stutter: an exploratory mixed model study. Journal of Fluency Disorders. 2010;35 (3):280-298.

25. Corbin JM, Strauss A. Grounded theory research: procedures, canons, and evaluative criteria. Qualitative Sociology. 1990;13(1): 3-21.

26. Glaser BG, Holton J. Remodeling grounded theory. In Forum Qualitative Sozialforschung/Forum: Qualitative Social Research. 2004:5(2).

27. Charmaz K. 'Grounded Theory: Objectivist and Constructivist Methods', in Denzin NK and Lincoln YS (eds) Strategies for Qualitative Inquiry (2nd Edition). Thousand Oaks, CA: Sage.

28. Strauss A, Corbin J. Basics of qualitative research: Grounded theory procedures and techniques. Newbury Park, CA: Sage. 1990.

29. Bowen GA. Naturalistic inquiry and the saturation concept: a research note. Qualitative Research. 2008;8(1):137-152.

30. Boyatzis RE. Transforming qualitative information: Thematic analysis and code development. Thousand Oaks, CA: Sage. 1998. 


\section{Appendix A.}

Semi-structured interview schedule questions:

-Can you please tell me about your experiences being a person who stutters?

-How would you describe stuttering to a person who does not stutter?

-What do you believe are the causes of stuttering?

-In what ways has stuttering impacted you when you were a child?

-In what ways has stuttering impacted you when you as an adult?

-Do you feel that there is a stigmatization that exists for people who stutter? Why/why not?

-Is there any additional information you would like to add? 


\section{Appendix B.}

Hello students. I would like to take a few moments to tell you a bit about the research project that I am conducting. Throughout this semester, I will be bringing in numerous guest speakers via Skype. Each guest speaker is an expert in stuttering and we will all be able to learn from that guest speaker in an interactive way that I hope you will enjoy. Using Skype to bring in guest speakers is common in other graduate majors (for example, all of my friends who teach in business courses across the country consistently bring in Skype guest speakers to their classroom), but Skype guest speakers seem to be a less common occurrence in the speech-language pathology major at most universities.

So I will be looking to get your feedback at the beginning and at the end of the semester on things related to our Skype guest speakers. You can provide this information to me in the optional surveys that I will hand out. There are only two surveys - one at the beginning of the semester and one at the end of the semester. The feedback that you provide to me in those optional surveys will help me better understand the potential educational benefits that Skype guest speakers can bring to this graduate course.

You are not required to fill out the surveys. If you do choose to fill out the surveys, you must not use your real name. Please use a fake name when filling out the survey. Also, please keep in mind that you must use the same fake name on both surveys you will fill out (one at the beginning of the semester and one at the end of the semester). Thank you. 


\section{Appendix C.}

1. Before starting this course, approximately how many people who stutter have you had the opportunity to meet (either face-toface or via video conferencing technology)?

2. At this very moment, how knowledgeable do you feel you are on the subject of stuttering?

-Extremely knowledgeable

-Quite knowledgeable

-Moderately knowledgeable

-Slightly knowledgeable

-Not at all knowledgeable

3. Aside from previous courses you have taken with Dr. Raj, as a speech-language pathology graduate student, have you ever been in a speech-language pathology class where the professor brought in a guest speaker or guest speakers?

-YES

-NO

-If you answered yes, describe your experience.

4. Aside from previous courses you have taken with Dr. Raj, as a speech-language pathology graduate student, have you ever been in a class where the professor utilized videoconferencing technology (such as Skype) to bring in a digital guest speaker or digital guest speakers?

-YES

$-\mathrm{NO}$ 


\section{Appendix D.}

1. At this very moment, how knowledgeable do you feel you are on the subject of stuttering?

-Extremely knowledgeable

-Quite knowledgeable

-Moderately knowledgeable

-Slightly knowledgeable

-Not at all knowledgeable

2. How much do you feel your knowledge on the subject of stuttering has improved as a result of the digital guest speakers?

-A great deal

-A lot

-A moderate amount

-A little

-None at all

3. How useful was the information that was provided by the digital guest speakers?

-Extremely useful

-Quite useful

-Moderately useful

-Slightly useful

-Not at all useful

4. If you could use one word to describe the use of videoconferencing technology to bring in digital guest speakers to the classroom, what would it be and why did you choose that word?

5. After completing this course, approximately how many people who stutter have you had the opportunity to meet (either faceto-face or via video conferencing technology)?

6. Do you believe that more professors teaching speech-language pathology courses could benefit from utilizing videoconferencing technology (such as Skype)? Why/Why not? 